\title{
How to Save Brand after Crises? A Literature Review on Brand Crisis Management
}

\author{
Ming Li, Haiying Wei \\ School of Management, Jinan University, Guangzhou, China \\ Email:Im920312@163.com \\ Received 21 January 2015; accepted 15 February 2016; published 18 February 2016 \\ Copyright (C) 2016 by authors and Scientific Research Publishing Inc. \\ This work is licensed under the Creative Commons Attribution International License (CC BY). \\ http://creativecommons.org/licenses/by/4.0/ \\ (c) (i) Open Access
}

\begin{abstract}
In recent years, brand crises are becoming increasingly prevalent in the global marketplace. Given that brand crises have many devastating effects, how to manage them effectively has become a hot topic among marketing researchers and practitioners. Based on the review of literatures concerned, this paper first analysed the concept and types of brand crises. Then this article summarized the response strategies that corporations can take during that hard time. Furthermore, this paper identified some factors that influence the effectiveness of those response strategies. Given all of this, the review highlights some promising directions for future research.
\end{abstract}

\section{Keywords}

Brand Crisis, Crisis Response, Brand Trust, Consumer Behavior

\section{Introduction}

Brand crises are becoming increasingly prevalent in today's marketplace. Some notable examples include Volkswagen's emissions scandal, McDonald and KFC's food scandal, labor violation of Apple's suppliers in developing countries. Such brand crises can be extremely devastating for the involved brands. For example, after American's Environmental Protection Agency ordered Volkswagen to recall about half a million vehicles, the company's stock price fell nearly 20 percent and may well be slapped $\$ 18$ billion in fines, according to Reuters. Except for the tremendous immediate loss from sales and costly compensation, brand crises can also have some far-reaching detriments on the involved brands in the long run such as consumer trust and brand equity (Van Heerde et al., 2007; Xu, 2015) [1] [2]. Considering the tremendous negative impact of brand crises, it is imperative to understand what brand crisis is and how to manage it in order to save the valuable yet fragile asset. 
To summarize and classify extant research and to better understand the past and present states of brand crisis management, this paper presents a comprehensive review of the literature, especially in Marketing. Starting with discussing the meaning and types of brand crises, this article systematically summarizes the response strategies that can be used during brand crises. Through reviewing the literature, we find four broad categories of crisis situational factors that may affect which crisis response to take and the effectiveness of the response. Finally, this article points out the implications for marketing researchers and practitioners, and proposes the further applications and extensions.

\section{Brand Crisis}

\subsection{Definition and Negative Effects of Brand Crisis}

Although the term brand crisis often appears in the commercial media, it was not got many empirical researches until Dawar and Lei (2009) formally proposed it in academic journal. Initially Dawar and Lei (2009) define brand crises as instances of well-publicized claims that a key brand proposition is unsubstantiated or false [3]. Given that the diversity of negative brand publicity, Dutta and Pullig (2011) conceptualize brand crises as unexpected events that threaten a brand's perceived ability to deliver expected benefits [4]. In this paper, we also use the latter definition to contain more related research. It is worth noting that some researchers also use the concepts such as product harm crises, brand misconduct, brand scandal, brand failure interchangeably (Dawar and Pillutla, 2000; Huber et al., 2010; Roehm and Tybout, 2006; Cheng et al., 2012) [5]-[8].

Brand crises are among a firm's worst nightmares, causing both short- and long-term negative effects such as immediate loss in own-brand sales, reduced effectiveness of marketing instruments, consumer trust (Van Heerde et al., 2007; Xie and Peng, 2009) [1] [9]. What's worse, brand crises also may spill over to the whole industry, even destory consumer's trust in society (Cleeren et al., 2013; Humphreys and Thompson, 2014) [10] [11]. In short, the negative effect of brand crisis has been proved constantly.

\subsection{The Types of Brand Crises}

There are two major theoretical perspectives to conceptualize brand crises into different types: 1) attribution theory perspective; 2) brand equity theory perspective.

According to the attribution theory (Weiner, 1985) [12], Coombs (2007) suggests each crisis has specific levels of crisis responsibility and his SCCT (Situational Crisis Communication Theory) has identified three crisis types based on attributions of crisis responsibility: 1) victim crisis, which the brand has very weak attributions of crisis responsibility and the brand is viewed as a victim of the event; 2) accidental crisis, which the brand has minimal attributions of crisis responsibility and the negative event was considered unintentional or uncontrollable; 3) intentional crisis, which the brand has very strong attributions of crisis responsibility and the event was considered to be purposely [13].

According to the brand equity theory (Keller, 1993) [14], consumers can potentially derive functional and symbolic benefits from a brand, thus Dutta and Pullig (2011) conceptualize brand crises as being two broad types [4]: 1) performance-related crises, which are also called product-harm crises, commonly involves defective or dangerous products that may reduce a brand's perceived ability to deliver functional benefits (Dawer and Pillutla, 2000) [5]. Lenovo's power cord recall in 2014 is an example of this crisis type. 2) Values-related crises, which do not directly involve the product, but involves social or ethical issues surrounding the values espoused by the brand. Carrefour's price gouging, Nike's sweatshop problem, Colgate's false advertising are examples. Similarly, based on research of how consumers process negative information, Votolato and Unnava (2006) identify two types of brand crises: 1) competence-based crises, which concern companies' competence in making a product. For example, a company may use cheaper raw materials that results in product failure; 2) moral-based crises, which stem from a compromise of moral standards. For example, a company may use sweat shop labor to enhance its profits [15]. It should be noted that the two crisis types are better understood as being aligned in a continuum, where many factors should play to pull a crisis to one direction or the other. For example, after receiving some complaints about Nikon D600, Nikon denied its products had flaw which pushed the crisis to the values-related crisis as consumers got angrier and upset about this famous company's failure in meeting its social obligation to provide qualified products. 


\section{Corporate Response Strategies to Brand Crises}

After a brand crisis, how the firm responds eventually determines the extent to which the brand can be saved. However, there is no standardized response typology as firm response to crises varies a lot. For instance, McLaughlin et al. (1983) suggest all strategies can be arrayed along a mitigation-aggravation continuum as follows: silence, concession, excuse, justification and refusal [16]. Benoit (1997) summarizes five broad categories of image repair strategies after crises: deny, evasion of responsibility, reducing offensiveness of event, corrective action, mortification [17]. Using the accommodative-defensive continuum, Coombs (1998) classifies crisis communication strategies into seven categories: attack the accuser, denial, excuse, justification, ingratiation, corrective action, full apology [18].

As we can see, there is no consensus among researchers about the details of crisis response strategies, however, all those response strategies can be placed between a deny-apology continuum, where the involved brand accepts responsibility or not. Along this method, Dawar and Pillutla (2000) suggest firm response can be considered along a continuum from unambiguous support to unambiguous stonewalling. Unambiguous support consists of accept responsibility, an apology to consumers or other affected stakeholders, and some form of remedy, such as a voluntary product recall or free replacement. On the contrary, stonewalling consists of a denial of responsibility and absence of remedial measures or no communication at all [5].

Besides those broad response strategies mentioned above, some researchers also explored some specific response strategies further. Ahluwalia et al. (2000) discuss two kinds of deny strategies: counter argumentation and diagnosticity. The former response strategy focuses on providing consumers with counterarguments that argue against the brand scandal by questioning its validity. The latter one, in contrast, focuses on reducing the value of the negative information for discriminating between alternative brands in the product category [19]. Xie and Peng (2009) also examined the roles of three kinds of apologetic response strategies aiming at repairing customer trust. Affective repair efforts include a corporate apology toward consumers and the general public, as well as expressions of regret and compassion toward victims. Functional repair efforts often involve financial compensation in order to remedy what has occurred, which can be in the form of a voluntary product recall, coupons for next purchase. Information repair efforts include appropriate communication, such as demonstrating evidence, clarifying facts, and disclosing updated news during the crisis handling process [9]. By looking into the specific response strategies, researchers can gain insights about how to use those response strategies more properly.

\section{Factors That Influence the Effectiveness of Response Strategies}

As various response strategies have their own advantages and disadvantages, researchers have come to the agreement that the relative efficacy of response strategies depends on crisis situation. Through a comprehensive review of the literature, this paper identifies that there are four broad categories of crisis situational factors that affect which crisis response to choose and the effectiveness of the response. Managers should evaluate the situation to determine which crisis response is best for the situation (Coombs, 2007) [13].

\subsection{Characteristics of Brand Crisis}

The characteristics of the brand crisis, such as the crisis responsibility, involved domain of the crisis, may influence the best type of response.

According to Situational Crisis Communication Theory, there are three clusters of crisis types, differing in organizational responsibility and there are also three clusters of response strategies that match these crisis types, differing in the amount of responsibility that the organization takes for the crisis by means of communication (Coombs, 2007) [13]. Crisis managers should utilize crisis response strategies with the requisite level of accepting crisis responsibility. In other words, the SCCT advises corporates to use deny strategies in case of a victim crisis, diminish strategies in case of an accidental crisis and rebuild strategies in the case of a preventable crisis. For instance, Claeys and Cauberghe (2014) confirm that for a preventable crisis, the best response strategy is taking full responsibility and apologizing to consumers (i.e., rebuild strategy) [20].

For crises occurred in different domains, researchers also find corporates need to take different response strategies. Dutta and Pullig (2011) find that for performance-related crisis, corrective action is the best response strategy, but for values-related crisis, reduction of offensiveness has the same effect compared to the costly cor- 
rective action. They infer that is because consumers value functional benefits more than symbolic benefits when they consider buying a product [4]. But Raju and Rajagopal (2008) find moral-based crisis is more harmful than competence-based crisis in term of decreasing consumers' trust. Thus, corporates should deny for moral-based crisis to avoid the potential negative outcomes and apology for competence-based crisis. However, when the crisis allegation is found to be true, even for moral-based crisis, corporates need to accept the fault and start to work on repairing the damage [21].

\subsection{Characteristics of Brand or Corporate}

As relationship principles have virtually replaced short-term exchange notions in both marketing thought and practice, branding theory has been built on relationship theory to a great extent (Fournier, 1998) [22]. Just like interpersonal interaction, the characteristics of the brand or corporate may influence consumers' reaction to its response strategy and then affect its effectiveness.

Aaker et al. (2004) find consumers' relationships with sincere brands suffered in the wake of transgressions (i.e., brand crisis), whereas relationships with exciting brands showed signs of reinvigoration after such transgressions. In other words, after apology and recovery, consumers' relationship strength with exciting brands become even higher than the status before the transgression happened, but no signs of recovery with sincere brands despite subsequent reparation attempts [23]. The results reveal that consumers have different expectation and form different relationship pattern with brands owning different personality.

Puzakova et al. (2013) find negative downstream consequences of brand humanization, that is, consumers' brand evaluations toward humanizing brand will decrease more heavily than non-humanizing brand. This is because consumers perceive brands endowed with human features as being mindful and possessing intentions. Thus, after a brand crisis, consumers will attribute more responsibility to humanizing brand [24].

Besides the personality or human features of the brand, the brand reputation or brand equity may also influence the effectiveness of response strategies. For example, Brady et al. (2008) find that high brand equity lead to more favorable satisfaction evaluations and behavioral intentions than low brand equity. The brand equity effect is identified as a prevailing advantage that spans the entire failure and recovery sequence [25].

\subsection{Characteristics of Consumers}

As the receiver of corporates' response strategy, consumers have the right to determine whether to forgive the brand or not. Researchers have found some interesting characters of consumers that may influence the effectiveness of the corporate response strategies.

Laufer is the first scholar that systematically studies the role of demographic variables in sharping consumers' reaction to brand crises. Laufer and Gillespie (2004) explore differences in blame attributions between men and women after brand crises. They find women blame a company more than men for that negative experience. What's more, they discover the underlying mechanism is women feel more personally vulnerable to the crisis occurring to them [26]. Samaraweera et al. (2014) examine whether the national culture can shapes consumers' reaction to corporate crisis response strategies. They find that duo to the difference of uncertainty avoidance between China and Sri Lanka, the scandal brand has to take a supper effort response in Sri Lanka whereas the voluntary recall response in China is sufficient in order to maintain moral reputation [27].

Besides these demographic variables, researchers also have explored some individual factors that may play roles in brand crises. Monga and John (2008) explore the impact of consumers' thinking style on the effects of brand crises. Through 3 studies, the results reveal that holistic thinkers are less susceptible to brand crisis than analytic thinkers. Thus, after a brand crisis, holistic thinkers' brand attitude and beliefs are higher than analytic thinkers. This is because holistic thinkers are more likely to consider external context-based explanations for brand crises [28]. Haselhuhn et al. (2010) find implicit beliefs will influence trust recovery in the interpersonal interaction context. Their experimental results indicate that individuals who believe moral character can change over time (incremental beliefs) are more likely to trust the transgressor following an apology than are individuals who believe that moral character cannot change (entity beliefs) [29]. Along this logic, Puzakova et al. (2013) explore three firm response strategies (i.e., denial, apology, and compensation) that can affect consumers' evaluation for anthropomorphized brands. Again, the result shows that consumers with entity beliefs are more difficult to satisfy than consumers with incremental beliefs. For entity beliefs consumers, compensation is the 
only effective response because they think it's hard for humanizing brands to change and behave well in the future [24].

\subsection{Characteristics of Consumer-Brand Relationship}

As mentioned earlier, recent research in consumer behavior indicates that consumers become attached to various brand and form relationships with them (Fournier, 1998) [22]. The relationships that consumers have for such brands are expected to vary in strength and may influence consumers' reaction to the response strategy.

Ahluwalia et al. (2000) find that commitment of the consumer toward the crisis brand can moderate the negative effect of brand crisis. In their studies, they find that consumers who are high commitment toward the brand are more likely to counter argue the negative information than consumers who are low commitment toward the brand, thus high commitment consumers' brand attitude are less likely to decrease. For corporate response strategies, the experiment results reveal that for high commitment consumers, a response strategy focusing on the perceived diagnosticity of the crisis information is more persuasive than the counter argumentation response. But for low commitment consumers, the counter argumentation response is more effective than the diagnosticity response [19].

Similarly, Dawar and Pillutla (2000) find that consumers interpret firm response on the basis of their prior expectations about the crisis firm. No matter which response strategy the firm takes, high expectation consumers are more likely to forgive the brand and the loss of brand equity are smaller than low expectation consumers [5].

Recently, researchers also find other relationship factors between consumers and the crisis brand, such as consumers' brand trust and crisis involvement can affect the effectiveness of corporate response strategies (Hegner et al., 2014; Claeys and Cauberghe, 2014) [20] [30].

\section{Conclusions and Future Directions}

In the uncertain markets, due to the increasing complexity of products, more demanding customers and more prevalent social media, brand crises occur more frequently (Dawar and Pillutla, 2000) [5]. Those brand crises have brought a lot of negative effects to the involved brands. Thus, it's very important for managers to response properly in order to restore trust and rescue a brand in crisis.

The goal of the present article is to summarize and integrate the literature on brand crisis management in marketing. Our findings highlight a contingency-based view on brand crisis management, which suggests that the relative efficacy of responses depends on crisis situational factors. And through the literature viewing, this article identifies four broad categories of crisis situational factors, namely brand crisis related factors, brand or corporate related factors, consumer related factors and the relationship related factors. This is very meaningful for brand managers who need to be ready to respond to unpredictable negative brand publicity. The current article provides a framework for brand managers to craft just-right, just-in-time responses. It offers brand managers a systematic way to gauge what they should say and do during that hard time. Brand managers can analyze a brand crisis along the four broad crisis situational factors and then tailor their response according to the crisis situation.

Although previous researches reviewed in this paper have provided a great deal of insights to handle brand crises, this review highlights the fact that research on brand crisis in marketing is at a relatively early stage of development, especially considering the poor performance of so many brands in reality around the world. Thus, this review proposes some promising directions for future research.

\subsection{From What to Do to How to Do}

As mentioned above, much of the research on corporate response strategy has almost unilaterally focused on the question of what the scandal brand should do after a brand crisis, namely the scandal brand should deny, or apologize, or compensate (Dutta and Pillutla, 2011; Puzakova et al., 2013) [4] [24]. But there is very fewer studies that investigate a later logical stage in a decision tree and a more focused question of how the scandal brand should deliver a specific response strategy. Take apology strategy as an example, there are many studies showing that apology is the most effective response strategy for brands that are responsible for a crisis (Raju and Rajagopal, 2008) [21]; nonetheless, scholars and laypeople alike have recognized the potential for apologies to fail. For instance, after the negative publicity of Jiugui’s liquor plasticiser, Jiugui Liquor Co apologized to con- 
sumers; however, consumers not only did not forgive this company, but also even became angrier for this company which did not acknowledge its responsibility in the apology letter. Similarly, Brinke and Adams (2015) find in the wake of corporate crisis that, how the CEO expresses facial emotion during apologies for corporate wrongdoing may affect investors' trust of the scandal brand. They find the expression of deviant affect (smiling) can be a signal of insincerity and then reduce investors' confidence in this company [31]. These examples illustrate what a company does matters, and also how to do which may be even more important.

Thus, one direction for future research is investigating the best way that corporates execute one specific response strategy. Researchers can examine this question in various dimensions by asking what, how, when, who to execute one response strategy. For example, it's very interesting to the role of message framing (emotional vs. rational) in crisis response (Claeys and Cauberghe, 2014) [20], it’s also very meaningful to explore who apologizes for the crisis is more effective, the CEO or the transgressor (maybe an employee of the scandal brand) (Hill and Boyd, 2015) [32]. By exploring all these questions, it can dig deeper and give more specific guidelines for companies to deliver responses properly.

\subsection{Focus on Other Potential Crisis Situational Factors}

It's worth noting that the four broad categories of crisis situational factors identified in this review is better to understand as a trial to form a contingency-based view on brand crisis management, but it may not be complete and perfect.

As we can observe from this review, characteristics of the brand/corporate and consumers are the two broad factors that are relatively less researched than other two broad factors. Future studies need to pay more attention to brand/corporate and consumer factors. For example, most existing research has overlooked the role of brand positioning in brand crisis context. But as we all know, there are some symbolic brands that highly focus on its symbolic values and also some functional brands that mainly focus on its functional benefits. It can be speculated that after a brand crisis, brands with different positioning may need different types of compensation (monetary compensation or emotional compensation). What's more, consumer related factors, such as consumer mindset (growth mindset vs. fixed mindset) may also influence trust recovery following brand crises (Murphy and Dweck, 2016), because growth-mindset individuals believe in people's ability to change, they were expected to perceive corporates' response strategies, such as an apology or promise of change, as sincere and thus more likely to forgive the scandal brands than individuals with fixed mindset that believe human traits are relatively fixed and hard to change [33].

Beyond the four broad categories of crisis situational factors, future research can also explore other contextual factors. For instance, researcher can explore the function and meaning of specific response strategy across different cultures. Maddx et al. (2011) find apologies in individual-agency culture (such as United States) are understood as a way to accept responsibility. But apologies in collective-agency cultures (such as Japan) are understood as a way to express remorse rather than a means to assign culpability [34]. Thus it would be especially interesting to examine these culture differences and it would be very useful for those multinational companies to handle brand crises in different countries.

\subsection{From Short-Term Responses to Long-Term Solutions}

Inevitably, the findings of this review have limitations, considering we mainly analyzed research that focus on how to respond instantly when brand crises occur. Even these researches can offer sound advice for managers to deal with brand crises, they provide little direction for managers to prevent crises and recover from them in a long term.

Given that brand crises have enormous immediate and far-reaching detriments, future brand crisis management studies would benefit from further investigating how to manage brand pre-crisis and post-crisis. Take post-crisis advertising as an example, existing research just have examined the effectiveness of advertising after brand crises (Liu and Shankar, 2015) [35], no study has explored the types of post-crisis advertising. It would be interesting to explore what kind of advertising should corporate use to reintroduce their products to market after brand crises. Would rational advertising that focus on product features can be more persuasive than emotional advertising that emphasize they relationship with consumers?

In closing, this review highlights that research on brand crisis management is in its infancy. Researchers have agreed on a contingency-based view of crisis response. And more research is needed to provide brand managers long-term solutions. 


\section{Acknowledgements}

This research was funded by the National Natural Science Foundation of China (71372169; 71302151), the Natural Science Foundation of Guangdong (2014A030311022); the Fundamental Research Funds for the Central Universities (15JNLH005); and Institute of Enterprise Development in Jinan University.

\section{References}

[1] Van Heerde, H., Helsen, K. and Dekimpe, G.M. (2007) The Impact of a Product-Harm Crisis on Marketing Effectiveness. Marketing Science, 26, 230-245. http://dx.doi.org/10.1287/mksc.1060.0227

[2] Xu, H.Y. (2015) Is Brand Equity an Asset or a Liability in Brand Harm Crisis? Buffering and Amplifying Effects and Contingent Conditions. Master Thesis, Brock University, Ontario.

[3] Dawar, N. and Lei, J. (2009) Brand Crises: The Roles of Brand Familiarity and Crisis Relevance in Determining the Impact on Brand Evaluations. Journal of Business Research, 21, 203-217. http://dx.doi.org/10.1016/j.jbusres.2008.02.001

[4] Dutta, S. and Pullig, C. (2011) Effectiveness of Corporate Responses to Brand Crises: The Role of Crisis Type and Response Strategies. Journal of Business Research, 64, 1281-1287. http://dx.doi.org/10.1016/j.jbusres.2011.01.013

[5] Dawar, N. and Pillutla, M.M. (2000) Impact of Product-Harm Crises on Brand Equity: The Moderating Role of Consumer Expectations. Journal of Marketing Research, 37, 215-226. http://dx.doi.org/10.1509/jmkr.37.2.215.18729

[6] Huber, F., Vollhardt, K., Matthes, I. and Vogel, J. (2010) Brand Misconduct: Consequences on Consumer-Brand Relationships. Journal of Business Research, 63, 1113-1120. http://dx.doi.org/10.1016/j.jbusres.2009.10.006

[7] Roehm, M.L. and Tybout, A.M. (2006) When Will a Brand Scandal Spill Over, and How Should Competitors Respond? Journal of Marketing Research, 43, 366-373. http://dx.doi.org/10.1509/jmkr.43.3.366

[8] Cheng, Y.Y., White, T.B. and Chaplin, L.N. (2012) The Effects of Self-Brand Connections on Responses to Brand Failure: A New Look at The Consumer-Brand Relationship. Journal of Consumer Psychology, 22, 280-288. http://dx.doi.org/10.1016/j.jcps.2011.05.005

[9] Xie, Y. and Peng, S.Q. (2009) How to Repair Customer Trust after Negative Publicity: The Roles of Competence, Integrity, Benevolence, and Forgiveness. Psychology and Marketing, 26, 572-589. http://dx.doi.org/10.1002/mar.20289

[10] Cleeren, K., van Heerde, H.J. and Dekimpe, M.G. (2013) Rising from the Ashes: How Brands and Categories Can Overcome Product-Harm Crises. Journal of Marketing, 77, 58-77. http://dx.doi.org/10.1509/jm.10.0414

[11] Humphreys, A. and Thompson, C.J. (2014) Branding Disaster: Reestablishing Trust through the Ideological Containment of Systemic Risk Anxieties. Journal of Consumer Research, 41, 877-910. http://dx.doi.org/10.1086/677905

[12] Weiner, B. (1985) An Attributional Theory of Achievement Motivation and Emotion. Psychological Review, 92, 548573. http://dx.doi.org/10.1037/0033-295X.92.4.548

[13] Coombs, W.T. (2007) Attribution Theory as a Guide for Post-Crisis Communication Research. Public Relations Review, 33, 135-139. http://dx.doi.org/10.1016/j.pubrev.2006.11.016

[14] Keller, K.L. (1993) Conceptualizing, Measuring, and Managing Customer-Based Brand Equity. Journal of Marketing, 57, 1-22. http://dx.doi.org/10.2307/1252054

[15] Votolato, N.L. and Unnava, H.R. (2006) Spillover of Negative Information on Brand Alliances. Journal of Consumer Psychology, 16, 196-202. http://dx.doi.org/10.1207/s15327663jcp1602_10

[16] McLaughlin, M.L., Cody, M.J. and O’Hair, H.D. (1983) The Management of Failure Events: SOME Contextual Determinants of Accounting Behavior. Human Communication Research, 9, 208-224. http://dx.doi.org/10.1111/j.1468-2958.1983.tb00695.x

[17] Benoit, W.L. (1997) Image Repair Discourse and Crisis Communication. Public Relations Review, 23, 177-186. http://dx.doi.org/10.1016/S0363-8111(97)90023-0

[18] Coombs, W.T. (1998) An Analytic Framework for Crisis Situations: Better Responses From a Better Understanding of the Situation. Journal of Public Relations Research, 10, 177-191. http://dx.doi.org/10.1207/s1532754xjprr1003_02

[19] Ahluwalia, R., Burnkrant, R.E. and Unnava, H.R. (2000) Consumer Response to Negative Publicity: The Moderating Role of Commitment. Journal of Marketing Research, 37, 203-214. http://dx.doi.org/10.1509/jmkr.37.2.203.18734

[20] Claeys, A.S. and Cauberghe, V. (2014) What Makes Crisis Response Strategies Work? The Impact of Crisis Involvement and Message Framing. Journal of Business Research, 67, 182-189. http://dx.doi.org/10.1016/j.jbusres.2012.10.005

[21] Raju, S. and Rajagopal, P. (2008) Responding to Ethical and Competence Failures. Advances in Consumer Research, 35, 855-856. 
[22] Fournier, S. (1998) Consumers and Their Brands: Developing Relationship Theory in Consumer Research. Journal of Consumer Research, 24, 343-353. http://dx.doi.org/10.1086/209515

[23] Aaker, J., Fournier, S. and Brasel, S.A. (2004) When Good Brands Do Bad. Journal of Consumer Research, 31, 1-16. http://dx.doi.org/10.1086/383419

[24] Puzakova, M., Kwak, H. and Rocereto, J.F. (2013) When Humanizing Brands Goes Wrong: The Detrimental Effect of Brand Anthropomorphization Amid Product Wrongdoings. Journal of Marketing, 77, 81-100. http://dx.doi.org/10.1509/jm.11.0510

[25] Brady, M., Croninjr, J., Fox, G. and Roehm, M. (2008) Strategies to Offset Performance Failures: The Role of Brand Equity. Journal of Retailing, 84, 151-164. http://dx.doi.org/10.1016/j.jretai.2008.04.002

[26] Laufer, D. and Gillespie, K. (2004) Differences in Consumer Attributions of Blame between Men and Women: The Role of Perceived Vulnerability and Empathic Concern. Psychology and Marketing, 21, 141-157. http://dx.doi.org/10.1002/mar.10119

[27] Samaraweera, G., Li, C.G. and Qing, P. (2014) Mitigating Product Harm Crises and Making Markets Sustainable: How does National Culture Matter? Sustainability, 6, 2642-2657. http://dx.doi.org/10.3390/su6052642

[28] Monga, A. and John, D. (2008) When Does Negative Brand Publicity Hurt? The Moderating Influence of Analytic versus Holistic Thinking. Journal of Consumer Psychology, 18, 320-332. http://dx.doi.org/10.1016/j.jcps.2008.09.009

[29] Haselhuhn, M.P., Schweitzer, M.E. and Wood, A.M. (2010) How Implicit Beliefs Influence Trust Recovery. Psychological Science, 21, 645-648. http://dx.doi.org/10.1177/0956797610367752

[30] Hegner, S.M., Beldad, A.D. and Kamphuis op Heghuis, S. (2014) How Company Responses and Trusting Relationships Protect Brand Equity in Times of Crises. Journal of Brand Management, 21, 429-445. http://dx.doi.org/10.1057/bm.2014.12

[31] ten Brinke, L. and Adams, G.S. (2015) Saving Face? When Emotion Displays During Public Apologies Mitigate Damage to Organizational Performance. Organizational Behavior and Human Decision Processes, 130, 1-12. http://dx.doi.org/10.1016/j.obhdp.2015.05.003

[32] Hill, K.M. and Boyd, D.P. (2015) Who Should Apologize When an Employee Transgresses? Source Effects on Apology Effectiveness. Journal of Business Ethics, 130, 163-170. http://dx.doi.org/10.1007/s10551-014-2205-9

[33] Murphy, M.C. and Dweck, C.S. (2016) Mindsets Shape Consumer Behavior. Journal of Consumer Psychology, 26, 127-136. http://dx.doi.org/10.1016/j.jcps.2015.06.005

[34] Maddux, W.W., Kim, P.H., Okumura, T. and Brett, J.M. (2011) Cultural Differences in the Function and Meaning of Apologies. International Negotiation, 16, 405-425. http://dx.doi.org/10.1163/157180611X592932

[35] Liu, Y. and Shankar, V. (2015) The Dynamic Impact of Product-Harm Crises on Brand Preference and Advertising Effectiveness: An Empirical Analysis of the Automobile Industry. Management Science, 61, 2514-2535. http://dx.doi.org/10.1287/mnsc.2014.2095 